\section{Commentary: Rusty pipes, clever plumbing, and a quiet aorta}

\author{
Ronald K. Woods, MD, PhD, ${ }^{\mathrm{a}}$ and \\ Michael H. Salinger, MD ${ }^{b}$
}

We congratulate Stephens and colleagues, ${ }^{1}$ who thoughtfully orchestrated the surgical management of a very challenging scenario. The use of a covered stent graft to salvage an old extra-anatomic bypass graft exemplifies wise judgment and innovative thinking. Thankfully, I (R.K.W.) haven't had the privilege of trying to dig out a 30-year old Dacron graft, but I can easily envision various scenarios that might ensue, most of which end with audible bleeding-audible bleeding (you can hear the blood issuing forth) is bad. The case further highlights the fact that in a reoperative setting, even without alarming imaging findings, grafts placed years ago demand respect and caution. While the preoperative imaging demonstrated some irregularity to the graft not involved in the pseudoaneurysm, intraoperative inspection revealed marked friability. The authors also highlight the limitations of artificial materials and the need for lifelong follow-up. We completely agree. Despite the fact that (1) currentgeneration electropolished nitinol may be less vulnerable to in vivo electrochemical degradation processes and (2) thicker struts and anatomic location of contemporary aortic grafts limit stent frame exposure to fatigue and fracture (compared with peripheral arterial grafts), the nonzero risk of these events mandates the need for ongoing imaging surveillance..$^{2-6}$

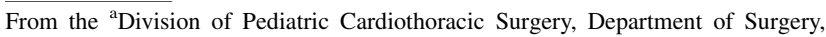
Herma Heart Institute, Children's Wisconsin, Medical College of Wisconsin; and ${ }^{\mathrm{b}}$ Department of Cardiovascular Medicine, Froedtert Hospital and the Medical College of Wisconsin, Milwaukee, Wis.

Disclosures: The authors reported no conflicts of interest.

The Journal policy requires editors and reviewers to disclose conflicts of interest and to decline handling or reviewing manuscripts for which they may have a conflict of interest. The editors and reviewers of this article have no conflicts of interest.

Received for publication April 13, 2020; revisions received April 13, 2020; accepted for publication April 14, 2020; available ahead of print June 30, 2020.

Address for reprints: Ronald K. Woods, MD, PhD, Division of Pediatric Cardiothoracic Surgery, Department of Surgery Medical College of Wisconsin, Children's Wisconsin, 9000 W Wisconsin Ave, MS B 730, Milwaukee, WI 53226 (E-mail: rwoods@chw.org).

JTCVS Techniques 2020;3:263-4

2666-2507

Copyright (C) 2020 The Authors. Published by Elsevier Inc. on behalf of The American Association for Thoracic Surgery. This is an open access article under the CC BY-NCND license (http://creativecommons.org/licenses/by-nc-nd/4.0/).

https://doi.org/10.1016/j.xjtc.2020.04.029

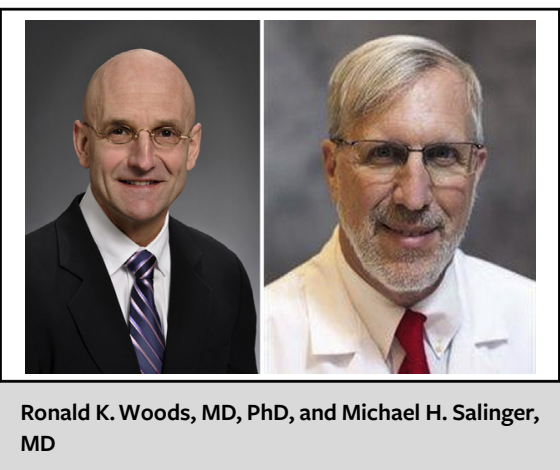

CENTRAL MESSAGE

A covered stent graft can be a good bail-out option in aortic surgery. Audible bleeding is bad.

We don't wish to downplay the important role of the authors' clever plumbing, but they did something else that is equally, if not more important. It is first-principle simple, nonsophisticated, yet crucial. They went on cardiopulmonary bypass with peripheral cannulation and dual arterial inflow and cooled before opening. It is this step that enabled clever plumbing and the survival of a neurologically intact patient. This arrangement provides all control options for all areas of the aorta and allows for full cardiopulmonary bypass, brief circulatory arrest, and antegrade cerebral perfusion. One potential addition would be an apical vent in the context of a regurgitant aortic valve should fibrillation occur while cooling.

In the authors' case, the preoperative imaging was compelling, but what degree of preemptive measures should be taken when the imaging is less concerning? I don't know the answer but can offer a personal opinion. In our specialty, a sample size of 1 to 3 may not pass for scientific rigor, but it can be more than sufficient for a surgeon to learn important, correct lessons. Compared with earlier in my career, I now practice with a much lower threshold for preemptive measures in a reoperative setting. Even with nonthreatening imaging and nonaortic surgery, I have a low threshold for establishing vessel exposure and purse strings at one peripheral site, particularly if access to that site is likely to be difficult. If given a choice, I will choose a groin seroma (even infection) over an ischemic stroke (or worse) secondary to a minute or two of significant bleeding and hypotension. It just takes one typically silent tear in the atrium fused to the sternum, or one very audible crack in the aorta. We salute the authors for a quiet aorta. 


\section{References}

1. Stephens EH, Fleischmann D, Starr A, Miller C. Repair of extra-anatomic bypass graft structural degeneration and pseudoaneurysm with endovascular stent-graft re-lining. J Thorac Cardiovasc Surg Tech. 2020;3: 259-62.

2. Stoeckel D, Pelton A, Duerig T. Self-expanding nitinol stents: material and design considerations. Eur Radiol. 2004;14:292-301.

3. Robertson S, Pelton A, Richies R. Mechanical fatigue and fracture of nitinol. Inter Mat Rev. 2012;57:1-36.
4. Allie D, Hebert C, Walker C. Nitinol stent fractures in the SFA. Endovasc Today. 2004;22-34.

5. Roos JE, Hellinger JC, Hallet R, Fleischmann D, Zarins CK, Rubin GD. Detection of endograft fractures with multidetector row computed tomography. J Vasc Surg. 2005;42:1002-6.

6. Ueda T, Takoka H, Petrovich I, Rubin G. Detection of broken sutures and metalring fractures in AneurRx stent grafts by using three dimensional CT angiography after endovascular abdominal aortic aneurysm repair: association with late endoleak development and device migration. Radiology. 2014;272:275-83. 